\title{
USE OF THE JONASSON'S MODEL TO ESTIMATE THE VAN GENUCHTEN PARAMETERS FROM TEXTURAL DATA OF SOME SOILS IN SOUTHERN ITALY
}

\author{
Alessandro Comegna, Angelo Sommella, Gerardo Severino
}

\section{Introduction}

In defining the hydraulic properties of unsaturated porous media, the field and laboratories methodologies that follow the instantaneous profile method $[10,24]$ have proved to be capable of producing correct hydraulic characterization. However, they require complex, costly equipment and great accuracy in measuring water content $\theta$ and potential $h[3,7]$.

An alternative method for estimating soil hydraulic properties is necessary, especially if large catchments are simulated, allowing for only basic soil data like soil texture and bulk density. This method is referred to as pedotranfer function technique (PTF) [2].

Several reviews on PTF development and use have been published $[15,22,26]$. Large databases, such as UNSODA [12] and HYPRES [26] are suitable for PTF development. PTFs, developed from regional databases, provide good results in regions having similar hydraulic and pedological characteristics. Some examples are provided by i) water retention PTFs developed in Belgium [23], which were more accurate than 13 others developed for the database in Northern Germany [19]; and ii) water retention PTFs developed in Italy [16], applicable to the Agri Basin in Basilicata. It is to be demonstrated, however, whether these observations can be generalised to other situations. We also need to understand which soils or other landscape characteristics shall prove to be similar in different regions for mutual reliability of the PTFs developed to be fully asserted.

A new approach in developing PTFs consists in using geophysical and/or topographic information as a direct input in the PTFs. Ground-penetrating radar, electric-conductivity meters, etc. all provide spatial coverage that shows a potential to be included in PTFs [17]. Terrain attributes were used to recalibrate

Paper received 02.01.2006; accepted 22.04.2006

Eng. Alessandro Comegna, phD; Prof. Angelo Sommella, Full Professor; Eng. Gerardo SeVErino, Assistant Professor, Department of Agricultural Engineering and Agronomy, University of Naples, ITALY. a PTF, and soil water retention exhibited strong dependence on terrain attributes in the study of Pachesky et al. [14].

Another frontier is the upscaling of PTF estimates: Scale dependence in soil hydraulic properties was recognized [5]. Currently these dependences are ignored and may limit PTF reliability, [16]. According to Tietje and Tapkenhinrichs [19], PTFs can be subdivided in three different groups: i) the point regression method which predicts the water content at certain matric potential by means of regression analysis $[8,15]$; ii) the functional parameter regression method which estimates the parameters of a closed form equation establishing the relationship between $h$ and $\theta$ using regression techniques $[15,24]$ and iii) the physical model method which uses the transformation between particle size (PSD) and pore size. This can be linear [8], non linear [1] or fractal $[20,4]$.

Physical models are usually preferred but they are complex; it is sometimes difficult to find appropriate parameters, and calculations are not easily done and require suitable hardware and software, like in Arya and Paris' model. Jonasson has recently provided a simple method to estimate the parameters in the van Genuchten soil water retention equation from PSD data similar to Arya and Paris' method [1]), albeit expressed in a more direct analytical way.

Given the relevance of this procedure in soil physics and hydrology, we evaluate Jonasson's predictive model potential which was tested in this study using a data set of 15 soil samples, by comparing water retention curves obtained with the above-mentioned model with those from experimentation.

\section{Materials and methods}

\subsection{Model}

Jonasson's prediction method consists of three steps: i) transforming the grain size distribution PSD into the $\theta(h)$ curve; ii) setting out parameters in the van Genuchten equation, and iii) combining steps i) and ii). Arya and Paris' model [1], if applied to each frac- 
tion of PSD curve, gives a discrete rather than continuous description of water retention curve $\theta(h)$. To modify Arya and Paris' method into a continuous analytical equation, Jonasson [10] suggests that Arya and Paris' equation be rewritten as follows:

$$
h_{\mathrm{s}}=0.0364 \cdot \frac{\left(720.7 \cdot W_{y}\right)}{e^{1 / 2} \cdot d_{\rho}^{L-y}}
$$

where

$$
\beta=\frac{3 \cdot\left(\alpha_{a p}-1\right)}{2}
$$

which specifies a continuous function of the head $h_{S e}$ as a function of $d_{p}$, which is the grain diameter at a cumulative percentage $P$ of the grain-size distribution, $e$ is the void ratio, $W_{f}$ is the weight fraction of soil (or a weighing factor) in a representative grain-size interval and $\alpha_{A P}$ is Arya and Paris' $\alpha$ factor.

Hydraulic parameters are set based upon the $\theta(h)$ curve, in a similar way as the graphical procedure proposed by van Genuchten. In Jonasson's method, pressure heads at two different effective saturations ( $\mathrm{Se}=25 \%$ and $75 \%)$ are used to describe the "head sorting", and thus to evaluate the $n$ parameter. It is further assumed that $m=1-1 / n^{\text {. }}$

Therefore, Jonasson obtained the relationship:

$$
n=-0.983+\frac{1}{1.0566 \cdot L-0.5487-L^{2}+0.1008 L^{3}}
$$

where

$$
L=\log \left(* / s_{0}\right)
$$

in which $h_{25}$ is the pressure head at $25 \%$ effective saturation and $h_{75}$ is the pressure head at $75 \%$ effective saturation.

If the $\mathrm{n}$ value is known, one can determine the value of $\alpha_{v G}$, by rearranging the van Genuchten equation as follows:

$$
\alpha_{i \in}=\frac{\left(s_{t}^{\frac{1}{\left(1-y_{t}\right.}}-1\right)^{X}}{h\left(S_{\theta}\right)}
$$

The value of $\alpha_{\nu G}$ may be obtained from any corresponding pair of $h$-Se data, but is evaluated here from either $h_{25}$ or $h_{75}$, since these two points are already known in the calculation procedure.

The two methods described above are combined to yield:

$$
\frac{h_{25}}{h_{75}}=\left(\frac{d_{75}}{d_{25}}\right)^{h+n}
$$

where $d_{25}$ is the grain diameter at 25 cumulative $\%$ by weight, and $d_{75}$ is the grain diameter at 75 cumulative $\%$ by weight.

Several authors [13] have suggested that the parameter $\alpha_{A P}$ can be approximately rewritten as follows:

$$
\alpha_{A F}=\exp \left(0.312 \cdot \log \left(d_{1} / s_{y}\right)\right)
$$

The values for $\alpha_{A P}$ and $\beta$ that give the best results for the prediction of $h$ from the grain size distribution of a given soil, can consequently be evaluated based upon known water retention curves and corresponding grain size distribution curves according to:

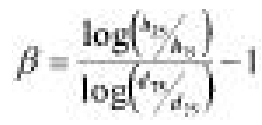

Finally, the $h_{75}$ parameter, and subsequently $\alpha_{V G}$ is calculated from $d_{75}$ using:

$$
h_{T s}=\frac{0.0364}{e^{y_{2}} \cdot d_{\mathrm{ss}}^{1+\beta}} \cdot\left(720.7 \cdot W, \gamma_{1}\right.
$$

where $h_{75}$ is in $\mathrm{m}$ and $d_{75}$ is in $\mathrm{mm}$.

\section{Applications}

The model illustrated above was used in assessing 15 soils of different texture from southern Italy (Fig. 1). Undisturbed soil cores were taken from the surface layer (Ap horizon) by driving a steel cylinder $(76 \mathrm{~mm}$ x $76 \mathrm{~mm}$ ) perpendicularly into the soil while carefully excavating soil from around the sampler. Then the core was removed; all cores were plugged at the top and bottom and stored at $4^{\circ} \mathrm{C}$ constant temperature before making laboratory measurements.

Laboratory measurements were performed on each soil core to determine: (i) particle-size distribution; (ii) bulk density; (iii) particle density; (iv) water content at saturation, and (v) the water retention curve.

Sand particle size distribution was determined using sieve analysis while silt and clay were determined using the hydrometer method [6]. Bulk and particle density was calculated on an oven-dry basis. Prior to determining the water retention curves, the soil cores were gradually saturated from below using the de-

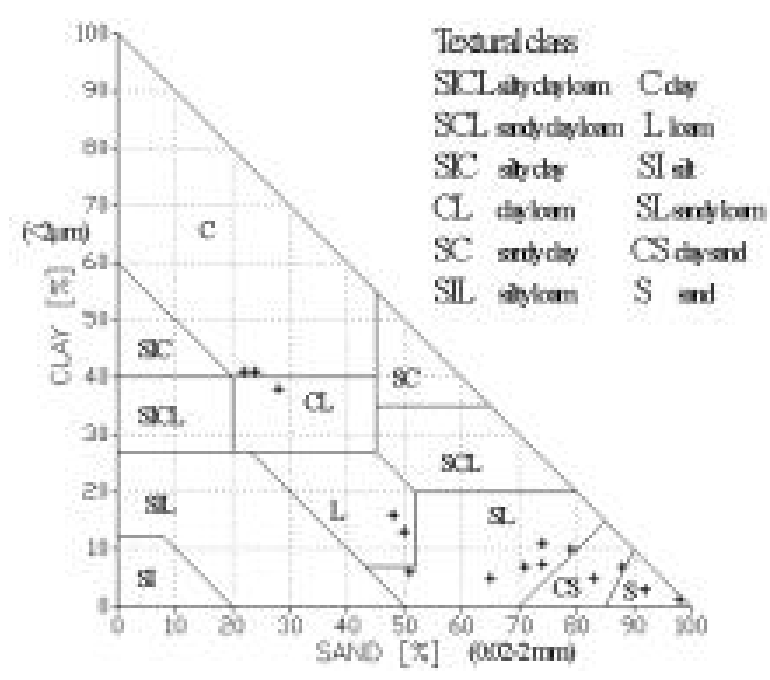

Fig. 1 - Clay and sand content of the test data set. 
aerated $0.01 \mathrm{M} \mathrm{CaCl}_{2}$ solution.

Water content at saturation was measured gravimetrically. Water retention data points of cores were obtained by means of a sand Kaolin-box apparatus consisting of two sets of ceramic tanks, each of which contains up to 20 soil cores [18].

For the drainage of the soil cores, to pressure weight potentials in the range from 0 to $-100 \mathrm{~cm}$, use was made of a reference Mariotte vessel to set values of the suction head. For pressure head potential, between -100 and $-300 \mathrm{~cm}$, soil cores were equilibrated using a bubbling tower. Water retention, at $-3000,-6000$ and $12000 \mathrm{~cm}$ pressure potential, were determined on disturbed soil samples by a membrane plate apparatus. The equilibrium water content corresponding to the monitored potential was measured gravimetrically.

The cumulative particle-size distribution PSD(d) are fitted with an adopted two parameters van Genuchten [22] equation [9].

$$
F(d)=\left[1+\left(\frac{d_{g}}{d}\right)^{-}\right]^{\prime \prime}
$$

where $d_{g}(\mathrm{~mm})$ is the particle size scale parameter and $m=1 \stackrel{g}{-} 1 / n$ is the dimensionless particle size slope parameter.

The $\theta(h)$ function is represented by fitting experimental $\theta(h)$ data to the parametric model of van Genuchten [22], which has been shown to describe hydraulic properties of a variety of soil with good accuracy.

The van Genuchten model describes the $\theta(h)$ function by:

$$
\begin{aligned}
& S_{c}=\frac{\theta-\theta_{s}}{\theta_{s}-\theta_{s}}=\frac{1}{\left[1+\alpha \cdot h^{n}\right]^{2}} ; \\
& m=1-1 / n
\end{aligned}
$$

where $\theta, \theta_{s}$ and $\theta_{r}$ are respectively the volumetric water content, saturated water content and residual water content, $h$ is the pressure potential and $\theta, n$ and $m$ are empirical shape parameters related to the pore-size distribution. The analytical $\theta(h)$ relation (Eq. 11), usually designed as the VG retention model, is defined by the unknown parameter vector $b\left(\theta_{s}, \theta_{r}, \theta, n\right)^{T}$ which are estimated by a non linear regression procedure which seeks to minimize:

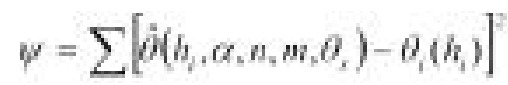

where $\theta_{i}(h)$ are the measured water contents and $\hat{\theta}\left(h_{i}\right.$, $\alpha, n, m, \theta_{r}$ ) are those predicted by the van Genuchten model. Minimization of the sum of squares objective function $\theta$, defined in Eq. 12, is achieved by the Levenberg-Marquardt algorithm. In most cases, the values $\theta_{r}$, are proved to be poorly defined from the statistical viewpoint. Therefore, in this study the parameter $\theta_{r}$ was fixed at zero, as this value was considered acceptable by some authors [25]. The parameter $\theta_{r}$, on the other hand, was found to play a relatively minor role at least with respect to influence exerted by the shape parameters $\theta$ and $n$, if comparison and use of soil hydraulic characteristics refer chiefly to wet regions of the retention curve.

\section{Results and discussion}

A series of calculations were thus made, which referred to the above Eqs. 1-9 to evaluate the relation $\theta(h)$ of each examined soil sample.

\begin{tabular}{|c|c|c|c|c|c|c|c|c|c|c|}
\hline $\mathrm{N}$ & SAND (\%) & SILT (\%) & C1.AY (\%) & $\rho_{b}\left(\theta-\mathrm{cmt}^{3}\right)$ & $\theta .\left(\theta \operatorname{cm}^{3}\right)$ & \multicolumn{3}{|c|}{ L.ab Dasa } & \multicolumn{2}{|c|}{ FMSE: } \\
\hline & & & & & & $a$ & $n$ & $m$ & Wrok & Wr-001 \\
\hline 1 & 24 & 35 & $4 t$ & 1.31 & 265 & 2739 & 2505 & 0.054 & 0.00721 & acsbo4s \\
\hline 2 & 22 & 37 & $4 t$ & 1.23 & 265 & 297 & 0.748 & 0208 & $0.0 t 819$ & 004775 \\
\hline 3 & 51 & 43 & 6 & 1.38 & 265 & 0.178 & 132 & 0.38 & 0000226 & 0010466 \\
\hline 4 & s3 & 12 & 5 & 1.15 & 246 & 3812 & 0.542 & 0300 & 0012275 & oossces \\
\hline s & 48 & 36 & 16 & 106 & 26 & 2635 & $0 \operatorname{sen}$ & 0253 & 6001625 & 0002721 \\
\hline 6 & 34 & ix & 7 & 10 & 200 & 2956 & 005 & $0 \times 21$ & 0006204 & $0.0105 \pi$ \\
\hline 3 & so & 36 & 13 & 117 & 254 & aots & 0.452 & $1.72 t$ & ooovers & 001as14 \\
\hline 8 & 65 & 30 & s & 0.8 & 253 & 4.737 & 1.581 & 0.15l & ouarek? & 0016475 \\
\hline 9 & 88 & s & 7 & 114 & 253 & 12444 & 1.72 & 6077 & 0031282 & 0665066 \\
\hline 10 & 28 & 35 & 38 & $1 \pi$ & 265 & 3065 & 2.551 & 0054 & $600047 \pi$ & 0,663181 \\
\hline 11 & 79 & 11 & 10 & 1.38 & 2.85 & 0.002 & 0.468 & 932 & 6014581 & 6014713 \\
\hline 12 & 74 & 15 & 11 & 1.6 & 202 & 0000 & 0.98 & $6 \cos$ & 9011794 & $001 \leq 575$ \\
\hline 13 & 92 & $s$ & 3 & 16 & 205 & 0.512 & 4223 & 0.145 & 0000584 & $0.0088 \pi$ \\
\hline 14 & $n$ & 22 & 7 & 1.56 & 268 & 3.306 & 1.324 & 027 & $1.7 \pi \mathrm{B}-\infty$ & 00007575 \\
\hline 15 & 98 & $\mathrm{t}$ & 1 & 1.85 & 263 & 5177 & 184587 & 601 & 0006493 & $\operatorname{acs} 49 n$ \\
\hline
\end{tabular}

In particular, the grain size-sorting $d_{75} / d_{25}$ is first calculated; then Eq. 7 and Eq. 2 gives $\alpha_{A P}$ and $\beta$; Eq. 6 leads to $h_{25} / h_{75}$; Eq. 4 subsequently gives $L$ and Eq.

TABLE 1 - Physical properties of the soils examined and RMSE of water content estimates. 
3 gives $\mathrm{n}$. The void ratio is calculated putting $e=\left(\rho_{p}-\right.$ $\left.\rho_{b}\right) / \rho_{b}$, where $\rho_{p}$ and $\rho_{b}$ are respectively the density of the particles and the bulk density of the mass of dried soil. Assuming $\theta_{r}=0$ and $W_{f}=0.01$, Eq. 9 results in $h_{75}$. Finally, inserting the values for $n$ and $h_{75}$ in Eq. 5 gives $\alpha_{V G}$.

The $\alpha$ and $n$ parameters calculated using this method are compared to $\alpha$ and $n$ parameters obtained from a direct non linear least squares fit to experimental retention data.

Furthermore, an optimisation procedure was performed for each sample, in order to determine the
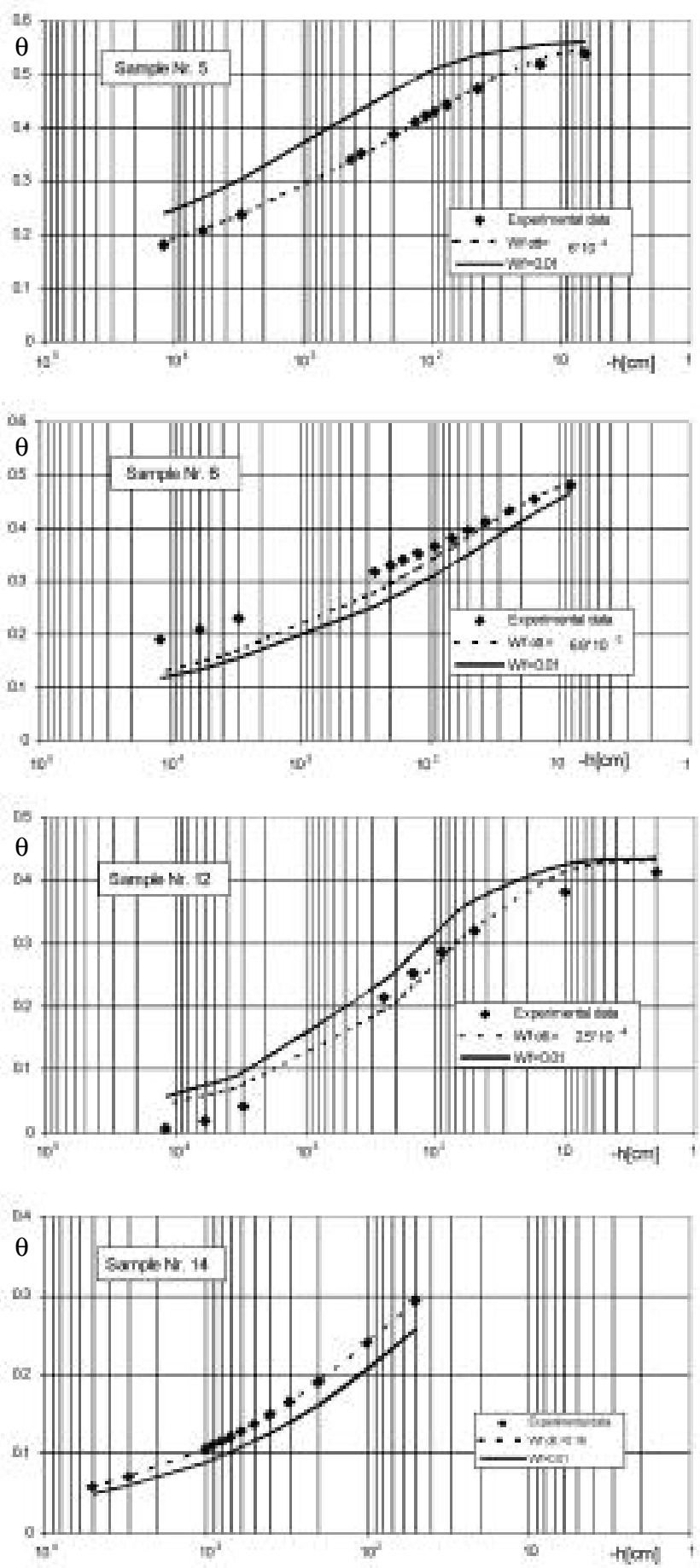

Fig. 2 - Comparison between measured and calculated $\theta(\mathrm{h})$ values.
$W_{f}$ factor which best fits the results of the model to the curve $\theta(h)$ obtained experimentally and fitted with van Genuchten' s model [22]; an optimised $W_{f}$ factor was determined by minimizing the objective function which referred to the above Eq. 12.

The results of the processing for all the soil samples, together with the experimental measurements, allowed us to represent $\theta(h)$ graphically. For the sake of brevity, the $\theta(h)$ trend relative to only a few soil samples, may be deduced from Fig. 2, in which the curves obtained with the $W_{f}=0.01$ approach and optimisation technique are compared. They are reported respectively with a solid line and a dashed line. The results obtained show good consistency between predicted and experimental $\theta(h)$ curves, only when the weighing $W_{f}$ was optimized. For all soils investigated, Table.1. summarizes the results of statistical analysis in terms of scatter of data points (RMSE).

Another interesting result is reported in Fig. 2, in which estimated retention curves were graphically compared according to Jonasson's PTF with a weighing factor $W_{f}=0.01$.

It can be seen that this PTF shows a bias in the compared retention curve. However, the shape of the retention curve is described correctly, which means that the water capacity $\partial \theta / \partial h$ of the estimated curve is similar to the water capacity of the data. Although the absolute differences in water content are not relevant for calculating the water fluxes, there can be a systematic bias in calculating the leaching of solutes due to the effect the water content has on the pore water speed and degradation process.

Because it is difficult to forecast the effects of differences between measured and predicted retention data on the water fluxes, it would be necessary to evaluate the applicability of this PTF in simulation models.

\section{Conclusions}

We have briefly reviewed the development and application of Jonasson's predictive model for estimating deterministic soil hydraulic properties from such particle-size distribution PSD data of different soils of Southern Italy.

The protocol yields relatively simple analytical expression for the parameters $\alpha$ and $n$ values in the van Genuchten equation, and needs only two characteristic grain diameter $-d_{25}$ and $d_{75}-$ and the soil bulk density.

Although there is substitute for actual measurement, the use of PSD data provides an easy source for inferring hydraulic properties.

However, a predictive model such as this one is only as reliable as the calibration data set, and caution is needed where the soil horizon under consideration differs significantly from the soil used in calibration.

Another consideration in the use of PSD data and related parameters is that they represent very small sampling volumes. 
Proper scaling of such parameters to obtain effective parameters at the grid-block scale of a numerical model is still an open issue, namely for unsaturated flow.

Further innovative studies are expected to supplement current theoretical and experimental knowledge in predicting soil hydraulic properties starting from more easily determined physical properties, also within the framework of a greater use and development of databases.

\section{References}

[1] ARYA L.M., PARIS J.F., A physicoempirical model to predict the soil moisture characteristic from particlesize distribution and bulk density data, Soil Sci. Soc. Am. J., (1981), 45, 1023-1030.

[2] Bouma J., VAN LANEN H.A.J., Transfer functions and threshold values: from soil characteristics to land qualities, In: Beek K.J., Burrough P.A., Mac Cornack D.E., Procedeedings of the international workshop on quantified land evaluation procedures. ITC Pubblication n.6, Enschede, (1986), 106-110.

[3] Ciollaro G., Comegna V., Ruggiero C., Confronto tra metodi di campo e di laboratorio per la misura delle caratteristiche idrauliche del suolo, Irrigazione e Drenaggio, (1989), 26, 67-72.

[4] Comegna V., Damiani P., Sommella A., Use of a fractal model for determining soil water retention curve, Geoderma, (1998), 85, 307-323.

[5] Feddes R.A., Menenti M., Kabat P., Is large-scale inverse modeling of unsaturated flow with areal average evaporation and surface soil moisture as estimated by remote sensing feasible?, J. Hydrology, (1993), 143, 125-152.

[6] Gee G.W., Bauder J.W., Particle size analysis, In: Klute, A. (Ed.), Methods of Soil Analysis: Physical and mineralogical Methods. SSSA Publisher, (1981), Madison, WI, 383-411.

[7] GReEn R.E., AhUya L.R., CHONG, Hydraulic conductivity, diffusivity and sorptivity of unsaturated soil, In: Klute, A. (Ed.), Methods of Soil Analysis: Physical and Mineralogical Methods. SSSA Publisher, (1986), Madison, WI, 771-789.

[8] GuPTA S.L., LARSON W.E., Estimating soil water retention characteristics from particle distribution, organic matter percent, and bulk density, Water Resour. Res., (1979), 15, 1633-1635.

[9] Haverkamp R., Parlange J.Y., Predicting the water retention curve from particle-size distribution: sandy soils without organic matter, Soil Sci., (1986), 142, 325-399.

[10] Hillel D., Fundamentals of Soil Physics, (1980), Academic Press, New York.

[11] JONASSON S.A., Estimation of soil water retention for natural sediments from grain size distribution and bulk density, Geologiska Institutionem CTH/GU, Publ. A 62, (1990), Goteborg, Sweden.

[12] LeiJ F.J., Alves W.J., Van Genuchten M.T., The UNSODA Unsaturated Soil Hydraulic Database: user's manual version 1.0, Cincinnati, (1996), Technical Report/Environmental Protection Agency $\mathrm{n}$. EPA/600/R-96/095.
[13] Mishra S., Parker C., Singhal N., Estimation of soil hydraulic properties and their uncertainty from particle size distribution data, J. Hydrology, (1989), 108, $1-18$.

[14] PachePsky Y.A., Timlin D.J., RaWls W.J., Soil water retention as related to topographic variables, Soil Sci. Soc. Am. J., (2001), 65, 1787-1795.

[15] Rawls W.J., Gish T.J., BRAKENSIEK D.L., Estimating soil water retention from soil physical properties and characteristics, Advances in Soil Science, (1991), 16, 213-234.

[16] Romano N., SANTini A., Effectiveness of using pedotransfer functions to quantify the spatial variability of soil water retention characteristics, J. Hydrology, (1997), 202, 137-157.

[17] Romano N., Palladino M., Prediction of soil water retention using soil physical data and terrain attributes, J. Hydrology, (2002), 265, 56-75.

[18] Stakman W.P., Walk G.V., van der Herst G.G., Determination of soil water retention curves: 1.Sandbox Apparatus, ICW Wageningen, (1969), Netherlands.

[19] TieTJe O., TAPKenhinRIChS M., Evaluation of pedotranfer functions, Soil Sci. Soc. Am. J., (1993), 57, 1088-1095.

[20] Tyler S.W., Wheatcraft S.W., Application of fractal mathematics to soil water retention estimation, Soil Sci. Soc. Am. J., (1989), 53, 987-996.

[21] VAn Genuchten M.TH., A closed-form equation for predicting hydraulic conductivity of unsaturated soils. Soil Sci. Soc. Am. J., (1980), 44, 892-897.

[22] Van Genuchten M.TH., LeiJ F., On estimating the hydraulic properties of unsaturated soils, In: van Genuchten M.T., Leij F.and Lund L.J. eds. Indirect methods for estimating the hydraulic properties of unsaturated soil: proceedings of the international workshop on idirect methods for estimating the hydraulic properties of unsaturated soils, Riverside, California, (1992), 1-14.

[23] Vereeken H., Maes J., Feyen J., Estimating the soil moisture retention characteristic from texture, bulk density and carbon content, Soil Sci., (1989), 148, 389-403.

[24] Watson K.K., An instantaneous profile method for determining the hydraulic conductivity of unsaturated porous materials, Water Resour. Res., (1966), 2, 709-715.

[25] Wosten J.H.M., VAn Genuchten M.TH., Using texture and other soil properties to predict the unsaturated soil hydraulic function, Soil Sci. Soc. Am. J., (1988), 52, 1762-1770.

[26] Wosten J.H.M., PAChePsky Y.A., RaWls W.J., Pedotranfer functions: bridging the gap between available basic soil data and missing soil hydraulic characteristics, J. Hydrology, (2001), 251, 123-150.

\section{SUMMARY}

In the light of potential application of deducing soil water retention from some simply determined physical properties, due consideration was given to physical and empirical models in the literature, based on the transformation of a granulometric curve PSD into a retention curve $\theta(h)$. In particular, forecasting po- 
tentials as proposed by Jonasson's model were evaluated in 15 soils from Southern Italy. The estimated $\theta(h)$ curves provided a good reliability only when the weighing factor $W_{f}$ was optimised. Even if the results obtained should be further verified in soils having different pedological characteristics, the model, used, may be particularly suitable to determine $\theta(h)$ curves, when experimental observations are poor or lack.

\section{Key words:}

particle-size distribution, water retention curve, predictive model. 